\title{
Alexander Grothendieck: A Country Known Only by Name
}

Pierre Cartier

To the memory of Monique Cartier (1932-2007)

This article originally appeared in Inference: International Review of Science, (inference-revi ew.com), volume 1, issue 1, October 15, 2014), in both French and English. It was translated from French by the editors of Inference and is reprinted here with their permission.

An earlier version and translation of this Cartier essay also appeared under the title "A Country of which Nothing is Known but the Name: Grothendieck and 'Motives'," in Leila Schneps, ed., Alexandre Grothendieck: A Mathematical Portrait (Somerville, MA: International Press, 2014), 269-88.

Alexander Grothendieck died on November 19, 2014. The Notices is planning a memorial article for a future issue.

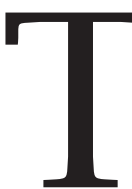

here is no need to introduce Alexander Grothendieck to mathematicians: he is one of the great scientists of the twentieth century. His personality should not be confused with his reputation among gossips, that of a man on the margin of society, who undertook the deliberate destruction of his work, or at any rate the conscious destruction of his own scientific school, even though it had been enthusiastically accepted and developed by firstrank colleagues and disciples.

Grothendieck's journey? A childhood devastated by Nazism and its crimes, a father who was absent in his early years and then disappeared in the storm, a mother who kept him in her orbit and long disturbed his relationships with other women. He compensated for this with a frantic investment in mathematical abstraction until psychosis, kept at bay through this very involvement, caught up with him and swallowed him in morbid anguish.

Grothendieck is difficult to categorize. Like Carl Friedrich Gauss, Bernhard Riemann, and many other mathematicians, he was obsessed with the notion of space. But his originality lay in

*NOTE: The following author information has been updated online and differs from the print version of this issue of the Notices: Pierre E. Cartier is an emeritus research professor at the Centre National de la Recherche Scientifique, a visitor at the Institut des Hautes Études Scientifiques, and an associate member of the Paris-Diderot University. His email address is cartier@i hes. fr.

DOI: http://dx.doi.org/10.1090/noti1235 deepening of the concept of a geometric point. ${ }^{1}$ Such research may seem trifling, but the metaphysical stakes are considerable; the philosophical problems it engenders are still far from solved. In its ultimate form, this research, Grothendieck's proudest, revolved around the concept of a motive, or pattern, viewed as a beacon illuminating all the incarnations of a given object through their various ephemeral cloaks. But this concept also represents the point at which his incomplete work opened to a void. Grothendieck's idiosyncrasy prompted him fully to accept this flaw. Most scientists are somewhat keener to erase their footprints from the sand, silence their fantasies and dreams, and devote themselves to the statue within, as François Jacob puts it.

From the depths of the isolation he has imposed upon himself since 1990, Grothendieck has sent us a vast, introspective work: Récoltes et Semailles (Crops and Seeds). ${ }^{2}$ If its existence has given rise

\footnotetext{
${ }^{1}$ On its fortieth anniversary, the IHÉS published my "La folle journée" (The Crazy Day), analyzing the concept of a geometric point by appeal to Grothendieck's ideas. See Pierre Cartier, "La folle journée, de Grothendieck à Connes et Kontsevich. Évolution des notions d'espace et de symétrie," Publications Mathématiques de l'IHÉS 88 (1998): 23-42.

${ }^{2}$ Alexander Grothendieck was not only my colleague, he was a very close friend. He sent me only one part of Récoltes et Semailles, the part that he thought I would be able to understand. For the missing part, I consulted the copy at the IHÉS library.
} 
among some to an unwholesome curiosity, I will nonetheless stick to offering as rational and honest an appraisal of the work as possible before permitting the book itself to elucidate the remarkable enterprise of a no less exceptional man.

\section{Biographical Elements}

A Family of Outcasts

There were three personalities: father, mother, and son, each in a unique way remarkable; and a phantom: an older half sister whom he did not know very well, on the mother's side, who died recently in the United States. To the best of my knowledge, the father's name was Schapiro, suggesting Hassidic roots. Breaking family tradition, Schapiro was drawn to Russia's revolutionary Jewish circles, and at the age of seventeen took part in the failed 1905 revolution against the Czar. He paid for this effort with more than ten years in prison and was only released during the 1917 revolution. This marked the beginning of an endless period of revolutionary wandering and the first of a long series of incarcerations. At last, after Franco's victory in Spain, he was reunited with his wife Hanka and their son Alexander, refugees in France. By then, his son attests, he was a broken man. He drifted aimlessly for a while; then, like so many other antifascist refugees, he was interned in ear1y 1939 in the Vernet Camp, until the Vichy authorities handed him to the Nazis, and he disappeared into Auschwitz. ${ }^{3}$

Hanka Grothendieck-Alexander took his mother's surname-was a northern German. During the 1920s, she was active in various far-left groups and tried her hand at writing. She already had a daughter when she met Schapiro. Alexander was born in Berlin in March 1928. ${ }^{4}$ She immigrated to France when Hitler came to power and eked out a meager existence in German émigré circles. Hanka and her son were interned in Mende in 1939, and would only find respite after the debacle of June 1940.

Alexander (he wasvenol long insistent upon this spelling) was abandoned by his parents when they left Germany. He remained hidden on a farm in northern Germany until 1938 (he was then ten years old), raised by a teacher of the Freinet school who believed in a return to Nature. He passed the years from 1942 to 1944 in Chambon-sur-Lignon, a pleasant resort town (in normal times) that was

\footnotetext{
${ }^{3}$ My colleague Szpiro confirmed this; his father was interned at Vernet for analogous reasons. These memories came to light sixty years later.

${ }^{4}$ The 1945 Götterdämmerung in Berlin destroyed all public records. Grothendieck thus experienced endless administrative problems. Until the beginning of the 1980s, he traveled with a Nansen passport from the United $\mathrm{Na}$ tions; these were documents issued to stateless people, albeit parsimoniously. After 1980, believing that he could no longer be drafted into the French army, he became a naturalized French citizen.
}

popular, for the most part, with Protestants. It housed a private high school, the Collège Cévenol, which until 1939 was largely a diploma mill for dim but wealthy Protestant youth. During the war, however, under Pastor Trocmé's energetic influence, the Collège Cévenol became a center of spiritual resistance to Nazism, one dedicated to the rescue of Jewish children. Grothendieck was a boarder at the Foyer Suisse and a student at the Collège. He left so strong an impression that even in the late 1950s, I was able to coax accounts of him from witnesses.

\section{Formative Years}

His childhood came to an end. He graduated from the Collège Cévenol and became a student at Montpellier in 1945. Then began the period of his scientific training.

His first explicitly mathematical episode occurred when he was an undergraduate. He described himself as very unhappy with the education given at the time. His professor told him that a certain Lebesgue had already solved all (!) the problems in mathematics, but that it would be too difficult to teach. So alone, with almost no guidance, Grothendieck reconstructed a very general version of the Lebesgue integral. In Récoltes et Semailles, he describes in detail the genesis of this first mathematical work, achieved in isolation; he honestly believed that he was the only mathematician in the world. ${ }^{5}$

When he arrived in Paris in 1948, mathematics degree in hand, his public period began. His professor from Montpellier had recommended him to his own former professor, Élie Cartan, unaware that Cartan was now much diminished, and that he had a son, Henri Cartan, who was as famous as his father and would henceforth dominate the Parisian-thus French-mathematical scene.

There was little love lost between Henri Cartan, the great Protestant university professor, and the young, self-taught rebel. André Weil thus suggested sending Grothendieck to Nancy; there, Jean Delsarte, one of the Bourbaki group's mentors, had skillfully promoted himself into a position as dean of faculty, making Bourbaki's infiltration possible. ${ }^{6}$ Jean Dieudonné and Laurent Schwartz knew how to discipline Grothendieck just enough to prevent him from overextending himself, and how to restrain his immoderate taste for extreme generality. They also knew how to give him

\footnotetext{
${ }^{5}$ I had a taste for mathematics, but I didn't know that one could make a career of it. My grandfather had graduated from the École des Arts et Métiers, and my uncle graduated from the École Centrale; my family's ambition was to see me enter the École Polytechnique!

${ }^{6}$ The association of Nicolas Bourbaki's collaborators was created in 1935. Its founding members were Henri Cartan, Claude Chevalley, Jean Coulomb, Jean Delsarte, Jean Dieudonné, Charles Ehresmann, René de Possel, Szolem Mandelbrojt, and André Weil.
} 
problems like Lebesgue's integration. Quickly, the disciple overtook his masters: alone, unaided, and isolating himself deliberately, he dominated the domain of Functional Analysis.

At the same time, a liaison with his landlady in Nancy led to the birth of a son, Serge. When a few years later Grothendieck sought to care for Serge himself, he embarked upon a custody lawsuit that had little chance of succeeding. But this was only the beginning of his chaotic family life: in all, he had five children by three mothers, and would be as absent a father to them as his own father was to him.

\section{The Golden Age at the IHÉS}

His mathematical work in Nancy had established his renown, and he might well have sailed along on that momentum. But he described himself well when he said that he was a builder of houses in which he was not meant to live. He embarked upon the classical career of a researcher, was quickly recruited to the CNRS (Centre National de la Recherche Scientifique, National Center for Scientific Research), promoted, and then spent a few years abroad after writing his dissertation. When he returned from São Paulo, he closed the chapter on Functional Analysis. That was the beginning of his master period, 1958 to 1970, which coincided with the Bourbaki group's prime. The springboard that allowed him to do this phenomenal work was given to him by Léon Motchane, a brilliant businessman who had thrown himself into the creation of the IHÉS (Institut des Hautes Études Scientifiques, Institute for Advanced Scientific Studies) in Buressur-Yvette. Motchane offered Dieudonné, who had just completed his theory of formal groups, the future institute's first chair in mathematics. Dieudonné accepted on the condition that he hire Grothendieck as well. The duo then recruited JeanPierre Serre, who with his keen sense of the unity of mathematics, high scientific culture, quickness of mind, and technical prowess, would keep them on their toes. Serre acted as an intermediary between Weil and Grothendieck when they no longer wished to communicate directly, and contributed greatly to the clarification of the Weil conjectures. Serre was the perfect beater of mathematical pheasants (I was going to say matchmaker), scaring the quarry straight into Grothendieck's nets, and in nets as strong as those, the quarry barely struggled.

Grothendieck was then moved to create one of the most prestigious mathematics seminars the world has ever seen. Surrounded by young talent, he threw himself with a passion into mathematical discovery, in sessions lasting from ten to twelve hours! $!^{7}$ He formulated a formidable program

\footnotetext{
${ }^{7}$ In Récoltes et Semailles, Grothendieck cites and names his twelve apostles. The central character is Pierre Deligne, who combines in this narrative the features of John, the apostle whom Jesus loved, and Judas. Ah, the weight of symbols.
}

intended to fuse arithmetic, algebraic geometry, and topology. A builder of cathedrals, as he put it in his own allegory, he distributed the work to his teammates. Every day, he sent interminable and illegible mathematical feuilletons to Dieudonné, who, sitting at his worktable from five to eight each morning, transformed the scribbles into an imposing collection of volumes co-signed by Dieudonné and Grothendieck and then published in the IHÉS' Publications Mathématiques. Dieudonné abjured all personal ambition and consecrated himself to this service with the same self-abnegation he had demonstrated under Bourbaki. He nonetheless only stayed at the IHÉS for a few years; upon the creation of the University of Nice, he became its first Dean of Sciences. But that did not end his collaboration with Grothendieck, and he even found the energy to organize the International Congress of Mathematicians in Nice, in $1970 .{ }^{8}$

The IHÉS team's success was immediate and resounding. As early as 1962, Serre declared that algebraic geometry and scheme theory were identical. ${ }^{9}$ Direct and indirect publications on the subject grew to the thousands of pages. After Grothendieck's retreat from mathematics, Pierre Deligne and Luc Illusie labored to finish publishing the Algebraic Geometry Seminars series, for which Grothendieck was ungrateful. Grothendieck's school closed in on itself; the generosity of spirit associated with it disappeared; a breath was stifled; but then, the same is true for Bourbaki's enterprise. $^{10}$

\section{The Break from High Society}

Grothendieck's scientific renown reached its apogee in 1966. He was to receive the crowning honor, the Fields Medal, at the International Congress of Mathematicians in Moscow. ${ }^{11}$ While the Soviet authorities were scant inclined to give him a visa (his father had become an "enemy of the people" after the 1917 revolution), they still believed they might leverage mathematicians in the highly virulent Cold War. (The small demonstration organized by Smale in Moscow nonetheless clearly showed them how difficult mathematicians were to manipulate.) Grothendieck did not show up.

It was thus, in the context of this event, as well as the opening of a social rift (Berkeley's fever, in 1965, led to May 1968 in France), that

\footnotetext{
${ }^{8}$ This consummated the rupture between Dieudonné and Grothendieck. The mutual incomprehension between the head of the congress, who believed in science for the sake of science, and the libertarian militant, who used the congress to propagate his revolutionary ideas, became complete.

${ }^{9}$ Grothendieck's creation.

${ }^{10}$ Common destiny of institutions and civilizations.

${ }^{11}$ We like to compare this to the Nobel Prize (which doesn't exist in mathematics), but it is limited to three or four laureates every four years.
} 
Grothendieck's fault line ruptured, or rather that his deepest wound was reopened. This wound was that of his Russian Jewish father, remembered in a country where anti-Semitism was resurgent; it was coupled with a "Nobel syndrome," particularly since the Fields Medal crowned an unfinished agenda and his suspicion that he would never reach the goal of his scientific ambitions. ${ }^{12}$ In parallel with this, the ambient social rift revealed to him his own contradictions. He, who saw himself as an outlaw and an anarchist, suddenly discovered that he was in fact a mandarin of the international scientific world, one who wielded authority over ideas and people. In a period when all authority was contested, he was ill at ease with this double personality. His temporary response was to found a tiny group that expressed itself in a newsletter called Survivre (Survival) and later Survivre et vivre (Survival and Life). This movement resembled one of those ecological-doom sects that sprung up in the 1970s, the danger (real at the time) of nuclear war merging with the obsession with pollution and overpopulation. He probably believed that social arguments, too, could be made using techniques of mathematical proof. In the end, he managed only to antagonize his audience.

There followed a few years of wandering: he resigned from the IHÉS on a relatively minor pretext ${ }^{13}$ in September 1970, traveled abroad, took a temporary position at the Collège de France, and finally a position as a professor at the University of Montpellier of his youth, a place for which he had only modest esteem. ${ }^{14}$

\section{The Interior Exile}

During his years in Montpellier, one event in particular was a milestone: his trial. Grothendieck had always welcomed marginal sorts into his home. In the 1970s, many hippie groups became attached

\footnotetext{
${ }^{12}$ The high point of a career that one imagines can't be surpassed.

${ }^{13}$ The discovery that the IHÉS received, on the recommendation of Michel Debré (then the French prime minister), a modest stipend from the DRET (Direction de la recherche et des études techniques, or the Directorate of Research and Technical Studies, part of the Defense Ministry, an organization financing military research). The IHÉS' financing was for a long time quite opaque, but military funding never played more than a modest role. It isn't totally absurd, however, to imagine that there might have been a global plan eventually to draft scientists in a new world war (this time against the USSR), and that the IHÉS might have been part of that network. Only Motchane could have enlightened us about this point.

${ }^{14} \mathrm{He}$ was an affiliated professor (a position reserved for foreigners) there from 1970 to 1972. At the very moment when he could have received tenure, he announced unambiguously that he would use his chair as a vehicle for his eco-anarchist ideas. This resulted in a curious three-way competition among Grothendieck, Jacques Tits, and me, very unusual for the Collège de France, which ended with Tits's nomination to the Chair of Group Theory.
}

to the regions of Lozère and Larzac, and seen from the outside, Grothendieck's house was the very embodiment of a phalanstery, he one of the gurus. Following a few incidents, real or exaggerated, the local police raided Grothendieck's house. The only crime that they could pin on him was his hosting of a Japanese Buddhist monk, a former mathematics student at the Tata Institute in Bombay and an entirely inoffensive character, but one whose residence permit in France had expired. The unexpected result was a summons, six months later, to the Magistrate's Court of Montpellier, by which time the Japanese monk had, of course, long since disappeared to the Antipodes. And what should have been a ten-minute expedited procedure became a major event. Grothendieck appeared at the Bourbaki Seminar in Paris to alert some of his colleagues: Laurent Schwartz, Alain Lascoux and me. By the day of the trial, the judge had received two hundred letters in favor of the accused, and a chartered airplane disgorged a medley of supporters wearing Dean's robes (with Dieudonné at their head), the ecclesiastical fringe of the champagne socialist set, legal heavyweights. Grothendieck acted as his own lawyer, preferring the risk of losing the trial to accepting concessions on form. He gave a magnificent speech for the defense. Alas, as Grothendieck had predicted, the craven judge sentenced him to a six-month suspended sentence. The sentence was upheld on appeal, but by then the media excitement had died away.

Grothendieck retired in 1988, and has lived since in an interior exile in a little village in Ariège (a department in the Midi-Pyrénées region of southwestern France). He seems to have broken off all family ties. It is not insignificant that he lives so close to the Vernet Camp, which is sadly infamous, but above all associated with his childhood. He has neither a telephone nor a known postal address, and only a select few know the exact location of his retirement, having promised not to divulge it. He lives alone, perceived by his neighbors as a "slightly eccentric retired mathematics professor." He has translated his spirituality into Buddhist terms, and kept from his orthodox Jewish ancestors a respect for dietary taboos: he practices the most extreme form of vegetarianism, and seems as a result to have compromised his health.

\section{The Birth of His Mathematical Work}

Presenting Grothendieck's scientific work in a few pages to a lay audience is a challenge. To do so, I will make use of the analysis offered by Dieudonné, long Grothendieck's closest associate, in his introduction to the Festschrift produced on the occasion of Grothendieck's sixtieth birthday. ${ }^{15}$

\footnotetext{
$\overline{{ }^{15} J e a n ~ D i e u d o n n e ́, ~ " D e ~ l ' a n a l y s e ~ f o n c t i o n e l l e ~ a u x ~ f o n d e-~}$ ments de la géométrie algébrique," in Pierre Cartier et al., eds., The Grothendieck Festschrift, (Basel: Birkhaeuser, 1990), 1-14.
} 


\section{Functional Analysis}

Georg Cantor's Set Theory allowed its twentiethcentury heirs to create Functional Analysis. This is an extension of the classical Differential and Integral Calculus (created by Leibniz and Newton), in which one considers not merely a particular function (such as the exponential function or a trigonometric function), but the operations and transformations that can be performed on all functions of a certain type. The new theory of integration, created at the beginning of the twentieth century by Émile Borel and above all by Henri Lebesgue, and the invention of normed spaces by Stefan Banach, Maurice Fréchet, and Norbert Wiener, yielded new tools for construction and proof in mathematics. Functional Analysis is a seductive theory in its generality, simplicity, and harmony, and it can resolve difficult problems elegantly. However, it often makes use of nonconstructive methods (the Hahn-Banach theorem, Baire's theorem and its consequences), which, when used to prove the existence of a mathematical object, cannot always provide an effective method for its construction. (Are there two irrational numbers $a$ and $b$ such that $a^{b}$ is rational? The obvious proof indicates that there are, but fails to identify the numbers). It is unsurprising that a beginner, delighted by the theory, responded enthusiastically to what he learned about Functional Analysis from his somewhat old-fashioned professors in Montpellier.

Upon his arrival in the Parisian mathematical world in 1948, at the age of twenty, Grothendieck had already written a voluminous manuscript in which he reconstructed a very general version of the Lebesgue integral. Once established in a favorable milieu in Nancy, where Jean Dieudonné, Jean Delsarte, Roger Godement and Laurent Schwartz (all active members of the Bourbaki group) were striving to go beyond Banach's work on Functional Analysis, he revolutionized the subject, and even in a sense annihilated it. In his thesis, written in 1953 and published in 1955, he created from scratch a theory of tensor products for Banach spaces and their generalizations, and invented the concept of a nuclear space in order to explain Laurent Schwartz's important kernel theorem about functional operators. Russian mathematicians influenced by Israel Gelfand would make essential use of nuclear spaces, and it would become one of the keys to applying techniques from probability theory to problems in Mathematical Physics (statistical mechanics, "constructive" quantum field theory). Grothendieck abandoned this after writing a dense and profound article on metric inequalities, one that fueled the research of an entire school (Gilles Pisier and his colleagues) for forty years. He cared little about the consequences of his ideas, and was indifferent, even hostile, towards theoretical physics, a discipline guilty of the destruction of Hiroshima.

\section{Homological Algebra}

Grothendieck then began a second mathematical career at the age of twenty-seven. It was 1955, the golden age of French mathematics, when mathematicians in Bourbaki's orbit, and under the leadership of Henri Cartan, Laurent Schwartz and Jean-Pierre Serre, attacked the most difficult problems of geometry, group theory, and topology. New tools appeared: sheaf theory and homological algebra (invented by Jean Leray in the first case, and by Henri Cartan and Samuel Eilenberg in the second: their treatise Homological Algebra was published in 1956). These were admirable in their generality and flexibility.

The apples of the Garden of the Hesperides were the famous conjectures stated by André Weil in 1949. These seemed to represent a combinatorial problem of daunting generality (counting the number of solutions for equations with variables in a Galois field), even though many significant special cases were already known.

Grothendieck's first foray into this new domain came as a thunderclap. It was known by the nickname "Tōhoku" because it appeared in the Japanese Tōhoku Mathematical Journal in 1957 under the modest title "Sur quelques points d'algèbre homologique" (Some Aspects of Homological Algebra). ${ }^{16}$ Homological algebra, intended to be a general tool that reached beyond all the special cases, was already a vast synthesis of known methods and results. But sheaves do not enter into this framework. Jean Leray constructed sheaves and their homology ad hoc, imitating the geometric methods of Élie Cartan (Henri Cartan's father). In the autumn of 1950 Eilenberg, who was spending a year in Paris, began with Cartan to give an axiomatic characterization of sheaf homology, yet the construction retained its ad hoc character. When Serre introduced sheaves into algebraic geometry in 1953, the seemingly pathological nature of the Zariski topology forced him into some very indirect constructions. Grothendieck's genius consisted in solving the problem from above, a method he would often use. Analyzing the success of homological algebras in the context of modules, he unearthed the notion of an abelian category (simultaneously invented by David Buchsbaum), and above all the condition he called AB5*. This condition guaranteed the existence of so-called injective objects. The sheaves satisfying condition $\mathrm{AB} 5 *$, the method of injective resolutions that is fundamental for modules, extends to sheaves in general without the need for any artifice. Not only does it lend a sound basis to the construction of

\footnotetext{
${ }^{16}$ Alexander Grothendieck, "Sur quelques points d'algèbre homologique, II" (Some Aspects of Homological Algebra), Tōhoku Mathematical Journal 9, no. 3 (1957): 119-21, doi:10.2748/tmj/1178244774.
} 
the Ext and Tor functors over to sheaves. Everything is natural again.

\section{Algebraic Geometry and Arithmetic Geometry} After this initiation (1955-1958), Grothendieck announced his research program: to create arithmetic geometry via a (new) reformulation of algebraic geometry, seeking maximal generality by appropriating the new tools created for use in topology and already tested by Cartan, Eilenberg, and Serre. He dared attack the synthesis that none of the actors at the time (Claude Chevalley, Serge Lang, Masyoshi Nagata, Jean-Pierre Serre, me) had dared, throwing himself headlong into the work with characteristic energy and enthusiasm. Grothendieck's undertaking thrived thanks to unexpected synergies: the immense capacity for synthesis and for work of Dieudonné, promoted to the rank of scribe; Serre's rigorous, rationalist and well-informed spirit; the practical know-how in geometry and algebra of Oscar Zariski's students; the youthful freshness of his great disciple Pierre Deligne-all acted as counterweights to Grothendieck's adventurous, visionary, and wildly ambitious spirit. The new IHÉS mobilized a constellation of young international talent. Organized around the key notion of a scheme, Grothendieck's theory ended up annexing every part of geometry, even the newest parts such as the study of algebraic groups. ${ }^{17}$ Using a gigantic apparatus-Grothendieck topologies (étale, crystalline...), descent, derived categories, the six operations, characteristic classes, monodromy groups, and so onGrothendieck arrived halfway to the final goal, the Weil conjectures. In 1974, Deligne completed the proof, but Grothendieck had, by 1970, and after twelve years of undisputed scientific reign over the IHÉS, lost his own organizing center and had let things fall apart. Until his official retirement in 1988 at the age of sixty, he worked only in spurts, nonetheless leaving a significant "posthumous" body of work.

There are three main texts: À la poursuite des champs (Pursuing Stacks), ${ }^{18}$ written in 1983, is a

\footnotetext{
${ }^{17}$ The epistemological shift was characteristic: for Chevalley, who invented the name in 1955, it indicated the scheme or skeleton of an algebraic variety, which remained the central object. For Grothendieck, the scheme is the focal point, the source of all the projections and all the incarnations.

${ }^{18}$ The mathematician Ronald Brown explains the complicated history of this document in "The origins of Alexander Grothendieck's 'Pursuing Stacks'." ...there are links to sites from which the manuscript may be downloaded in full or in parts. (inference-review. com/article/a-countryknown-on 1y-by-name\#footnote-18 and pages.bangor . ac . uk/ mas010/pstacks . htm) Brown also includes interesting correspondence among mathematicians about corrections to the text and about Grothendieck, the man and his work. The links from some of these entries point to other discussions among mathematicians about Grothendieck in general and this manuscript in particular.
}

six hundred-page reflection on multi-dimensional categories. Combinatorics, geometry, and homological algebra come together in an imposing project. After more than fifteen years of the combined efforts of many, three (probably nearly equivalent) definitions have been proposed for multidimensional categories (broadly defined) ${ }^{19}$ They are not only important for pure mathematics since a theory of such constructions would have many potential applications in theoretical computer science, statistical physics, etc. The second, Esquisse d'un programme (Sketch of a Program), ${ }^{20}$ was a text written in 1984 for inclusion in the application for a position with the CNRS. In it, Grothendieck sketches (the word is exact) the construction of a tower (or a game of Lego) describing deformations of algebraic curves. Finally, La longue marche à travers la théorie de Galois (Long March Through Galois Theory), ${ }^{21}$ written in 1981, gives partial indications about some of the constructions suggested in the Esquisse.

Those texts were all passed around handto-hand, with the exception of the Esquisse, which was finally published at the insistence of a group of devotees. Curiously, the true heirs of Grothendieck's work are essentially members of a Russian mathematical school (Yuri Manin, Vladimir Drinfeld, Alexander Goncharov, Maxim Kontsevitch, to cite just a few), who have had little if any direct contact with Grothendieck. Nonetheless, they inherited and knew how to make use of methods from mathematical physics, a domain he disregarded and abhorred.

\footnotetext{
${ }^{19}$ The challenge is this: when we want to formulate an identity at a certain level, say $A=B$, we must create a new object on the level just above, which performs the transformation from $A$ to $B$. It is, therefore, a kind of dynamic theory of relations. In spirit, it is analogous to a Russell-Whitehead theory of types, but with a geometric component; in fact, Grothendieck conceives of his stacks as generalizations of homotopy theory (which studies deformations in geometry). His fusion of logic and geometry, nascent in stacks and toposes, is one of the most promising doors Grothendieck opened.

${ }^{20}$ Alexander Grothendieck, "Esquisse d'un programme" (Sketch of a Program), 1984 manuscript, published in later form in Pierre Lochak and Leila Schneps, eds., Geometric Galois Actions: Volume 1. Around Grothendieck's Esquisse d'un Programme, London Mathematical Society Lecture Notes 242 (Cambridge: Cambridge University Press, 1997) 5-48; English translation 243-83.

${ }^{21}$ Alexandre Grothendieck [sic], "La longue marche à travers la théorie de Galois:" transcription d'un manuscrit inédit, Volume 1 (The Long March Through Galois Theory: Transcript of an Unedited Manuscript), edited and with a foreword by Jean Malgoire (Montpellier: Universite Montpellier II, Département des Sciences Mathématiques, 1995).
} 


\section{Autopsy of an CEuvre}

The Editing of the Geometric Corpus

Published in two series, Grothendieck's work in algebraic geometry amounts to more than ten thousand pages. Entitled Éléments de Géométrie Algébrique (Elements of Algebraic Geometry, or ÉGA), an appeal to both Euclid's Elements and Bourbaki, the first was written entirely by Dieudonné, and has remained unfinished; of the thirteen parts that were initially planned, only four were written. The second series, the composition of which was more tumultuous, is called Séminaires de Géométrie Algébrique (Seminars in Algebraic Geometry, or SGA) and comprises seven parts. It covers the Seminars in the Bois-Marie (named after the location of the IHÉS), which Grothendieck led from 1960 to 1969. The first two parts were written by Grothendieck, or under his control, and he personally supervised their publication; as for the third, it was essentially written by Pierre Gabriel and Michel Demazure (whose dissertation was extracted from this work). Afterward, things became more complex. When Grothendieck abandoned the mathematical scene in 1970, he left behind unfinished business, and the workplace was in a pitiful state. He left indecipherable manuscripts, mimeographed lectures from the seminars, notes for publication. They needed to be synthesized and the (sizeable) gaps filled in; it was an epic task. Luc Illusie and Pierre Deligne accomplished all of this with great fidelity and filial piety. The centerpiece, in view of the Weil conjectures, is SGA 4, dedicated to the most innovative of ideas. But when Deligne announced his proof of the Weil conjectures in 1974, experts considered the foundations of his proof to be incomplete. Deligne then published (along with the missing link from the Grothendieck seminar, SGA 5) an additional volume, which he basically drafted by himself, titled, curiously, SGA 41/2. Grothendieck dismissed the entire enterprise. This was not what he, Grothendieck, had had in mind; his plans had been truncated; they had betrayed him. He described his feelings by means of a strong image: that of a team of builders who, now that their Master is dead, disperse, each one carrying away his own sketches and tools. It would be a morally powerful image were it not for the fact that, far from dying, the Master had simply abandoned his team.

Grothendieck had a taste and a talent for naming things, which he used as a major intellectual strategy. Thus, my title, "A Country Known Only by Name," is an homage to his way with words. He had a special talent for naming things before possessing and conquering them, and many of his terminological choices were remarkable. He sought mental images to illustrate his scientific ideas; these included la belle demeure parfaite (the perfect mansion) and le beau château dont on a hérité (the beautiful, inherited castle). He described himself as a builder. He juggled all these allegories in a fantastic register of language. And this is all the more surprising and striking because his native language was German, the only language he used to communicate with his mother until her death. But if he long thought in German, he nevertheless subsequently acquired an acute sense of French; his bilingualism allowed him to play discerningly with Germanisms.

\section{The Great Problems}

Having a taste for symbolism, Grothendieck recognized twelve disciples, just as he divided Récoltes et Semailles into twelve themes, of which I will only comment on a few. A large number of the themes concern Grothendieck's grand enterprise: algebraic geometry. The great problems constitute great enigmas, whose relatively simple formulation offers no obvious point of attack. What was improperly known as Fermat's Last Theorem was a conjecture of Biblical simplicity: the relation $a^{n}+b^{n}=c^{n}$ is impossible if $a, b, c, n$ are whole numbers, unless $n=2$. Andrew Wiles and Richard Taylor required a large and complex edifice, based largely on Weil and Grothendieck's methods, to establish the proof. The most prestigious and confusing of contemporary problems is the Riemann Conjecture. In 1930, Helmut Hasse (following Emil Artin and Friedrich Schmidt) formulated and solved a problem similar to the Riemann Conjecture by translating it into the form of an inequality. The next step would occupy Weil from 1940 to 1948. When Weil formulated his famous conjectures in 1949, he was guided by these ideas.

For Grothendieck, the Weil conjectures are not so much interesting in themselves, but as a test of his general vision. Grothendieck distinguished between builders and explorers in mathematics, viewing himself as both at once. Grothendieck's favorite method was similar to Joshua's for conquering Jericho. One must seize the place by sapping it; at a certain point, it succumbs without a fight. Grothendieck was convinced that if one had a sufficiently unifying vision of mathematics, if one could sufficiently penetrate its conceptual essence, then particular problems would be nothing but tests that no longer need to be solved for their own sake.

This fashion of conceiving of mathematics worked quite well for Grothendieck, even if his dreams tended to make him go too far at times and he needed the correcting influence of Dieudonné and Serre. Deligne knew every trick of his master's trade by heart, every concept, every variant. His proof, given in 1974, is a marvel of precision; the steps follow each other in a natural order, without surprise. Every lecture by Grothendieck introduced a whole new world of concepts, each more general than the one before. I think that this opposition of methods, or rather of temperaments, is the true reason behind the personal conflict that pushed them apart. That John, the disciple Jesus loved, 
wrote the last Gospel by himself played a role, perhaps, in the sullen exile that Grothendieck imposed upon himself.

\section{The Method}

We now arrive at the very heart of the unifying vision of Grothendieck's mathematical method. Of the twelve great ideas of which he was justly proud, he placed three above the others. He offered them in the form of a progression from schemes to motives:

\section{$\mathrm{SCHEME} \rightarrow \mathrm{TOPOS} \rightarrow \mathrm{MOTIVE}$}

His whole scientific strategy was, indeed, organized around a progression of increasingly general concepts. The image that comes to my mind is a Buddhist temple that I visited in Vietnam in 1980. According to tradition, the altar comprised a series of rising steps, at the top of which lay an enormous reclining figure of the Buddha. When we follow Grothendieck's work throughout its development, we likewise sense that we're gradually evolving toward perfection. The motives represented, in his mind, the final stage, the one he hadn't yet reached. He had, however, reached the two intermediate stages (scheme and topos).

\section{The Trilogy}

\section{Schemes}

The term itself was coined by Chevalley, although accepted in a more restrictive sense than the term as used by Grothendieck. In Foundations of Algebraic Geometry, André Weil had introduced into algebraic geometry the methods used by his mentor, Élie Cartan, in differential geometry (following Carl Friedrich Gauss and Jean Darboux). But Weil's method was by no means intrinsic, and Chevalley wondered what was invariant, in Weil's sense of variety. The answer, inspired by Zariski's work, was simple and elegant: the scheme of an algebraic variety is the collection of local rings of the subvarieties found inside the rational function field. There is no need for an explicit topology, a point of distinction between Chevalley and Serre, who at roughly the same time introduced his algebraic varieties using Zariski topologies and sheaves. Each of the two approaches had advantages, but also limitations: Serre had an algebraically closed base field; Chevalley had to work only with irreducible varieties. In both cases, the two fundamental problems of products of varieties and base change could only be approached indirectly. All the same, Chevalley's point of view was better suited to future extensions to arithmetic, as Nagata soon observed.

Évariste Galois was certainly the first to notice the polarity between equations and their solutions. One must distinguish between the domain in which coefficients of the algebraic equation are chosen and the domain in which solutions are sought. Grothendieck created a synthesis out of these ideas, based in essence on the conceptual presentation of Zariski-Chevalley-Nagata. Schemes are thus a way of encoding systems of equations as well as the transformations to which one may subject them.

Grothendieck presented the Galois problem in the following manner: a scheme is an absolute object, $X$, say; the choice of a field of constants (or a field of definition) corresponds to the choice of another scheme $S$ and a morphism $\pi_{X}$ from $X$ to $S .{ }^{22}$ In the theory of schemes, a commutative ring is identified with a scheme, its spectrum. ${ }^{23} \mathrm{~A}$ homomorphism from ring $A$ to ring $B$ likewise maps, inversely, the spectrum of $B$ into the spectrum of $A$. Moreover, the spectrum of a field has a single underlying point (even though many different points exist, in this sense); consequently, giving the field of definition as being included in the universal domain corresponds to giving a scheme morphism $\pi_{T}$ from $T$ to $S$. A solution of the system of equations $X$, with the domain of constants $S$, with values in the universal domain $T$, corresponds to a morphism $\varphi$ from $T$ to $X$ such that $\pi_{T}$ is the composition of $\varphi$ and $\pi_{T}$

What admirable simplicity! Modern mathematics rests upon the primacy of sets. Once one has accepted the existence of sets and the constructions made from them, every mathematical object becomes a set and coincides with the set of its points. ${ }^{24}$ Transformations are, in principle, transformations of points. ${ }^{25}$ In the various forms of geometry (differential, metric, affine, algebraic), the central object is the variety, considered as a set of points. ${ }^{26}$ And for Grothendieck, the scheme is the internal mechanism, the matrix that generates the space's points. ${ }^{27}$

The purely mathematical analysis, Gelfand's and then Grothendieck's, of the notion of a point was discovered after a fundamental reevaluation of the status of the point in quantum

\footnotetext{
${ }^{22}$ From the start, this is based on the philosophy of categories: we define the category of schemes, with its objects (the schemes) and its transformations (morphisms); a morphism $f$ links two schemes $X$ and $Y$, which is symbolized by $f: X \rightarrow Y$.

${ }^{23}$ Gelfand's fundamental idea was to associate a normed commutative algebra to a space. Grothendieck dated his first investment in functional analysis to exactly the time, post-1945, when Gelfand's theory assumed its centrality. The term "spectrum" comes directly from Gelfand.

${ }^{24}$ This set must be structured, which is done using a settheoretic version of Bertrand Russell and Alfred North Whitehead's theory of types.

${ }^{25}$ But the possibility of considering, say, lines or circles in space as points of a new space makes it possible to incorporate the geometry of transformations of points into lines or circles.

${ }^{26}$ In the sense of the domain of variation.

${ }^{27}$ I am using the word "matrix" here in its customary sense, not in the usual mathematical sense (a table of numbers).
} 
physics. The most systematic expression of this reevaluation is Alain Connes' noncommutative geometry. The synthesis is far from complete. The increasingly manifest kinship between the Grothendieck Teichmüller ${ }^{28}$ group and the renormalization group in quantum field theory is doubtless only the first manifestation of a symmetry group operating on the fundamental constants of physics, a kind of cosmic Galois group. ${ }^{29}$ Grothendieck did not predict this development, and probably would not even have welcomed it, owing to his prejudices against physics (due in large part to his vehement rejection of the military-industrial complex).

In Récoltes et Semailles, Grothendieck for a moment compared himself to Einstein in his contribution to the problem of space. His contribution is indeed of the same magnitude. ${ }^{30}$ Einstein and Grothendieck both deepened a particular vision in which space is not an empty receptacle for phenomena, but the principal actor in the life of the world and the history of the universe.

\section{Toposes}

Let us now consider toposes. ${ }^{31}$ Unlike schemes, toposes generate geometry without points. In fact, nothing prevents us from proposing an axiomatic framework for geometry in which points, lines, and planes would all be on the same footing. Thus we know axiomatic systems for projective geometry (George Birkhoff) in which the primitive notion is that of a plate (a generalization of lines and planes), and in which the fundamental relationship is that of incidence. In mathematics, we consider a class of partially ordered sets called lattices; each of these corresponds to a distinct geometry. ${ }^{32}$

In the geometry of a topological space, the lattice of open sets plays a starring role, while points are relatively minor. But Grothendieck's originality was to reprise Riemann's idea that multivalued functions actually live not on open sets of the complex plane, but on spread-out Riemann surfaces. The spread-out Riemann surfaces project down to each other and thus form the objects of a category. However, a lattice is a special case of

\footnotetext{
${ }^{28}$ Named by Drinfeld, one of the mathematicians who penetrated most deeply into Grothendieck's Esquisse.

${ }^{29}$ Most notably in Dirk Kreimer and Alain Connes' recent reformulation.

${ }^{30}$ Also, don't forget Einstein's deep commitment to the struggle against militarism, following a political trajectory closely related to Grothendieck's.

${ }^{31}$ Some purists would like the plural to read "topoi," as in classical Greek. I will follow Grothendieck, writing "topos" and "toposes."

${ }^{32}$ We must assume the existence of a largest and smallest element (the empty set and the universal set), and of intersections and joins of two plates. In the past twenty years, this point of view was developed anew under the name "matroid" or "combinatorial geometry" (mainly by Gian-Carlo Rota and Henry Crapo).
}

a category, since it includes at most one transformation between two given objects. Grothendieck thus proposed replacing the lattice of open sets with the category of spread-out open sets. When adapted to algebraic geometry, this idea solves a fundamental difficulty, since there is no implicit function theorem for algebraic functions. Sheaves can now be considered as special functors on the lattice of open sets (viewed as a category), and can thus be generalized to étale sheaves, which are special functors of the étale topology.

Grothendieck would successfully play many variations on this theme in the context of various problems of geometric construction (for example, the problem of modules for algebraic curves). His greatest success in this regard would be the étale " $\ell$-adic" cohomology of schemes, the cohomological theory needed to attack the Weil conjectures.

But there is still another step towards abstraction. Consider the progression:

\section{SCHEME $\longrightarrow$ ÉTALE COHOMOLOGY $\rightarrow$ ÉTALE SHEAVES}

Grothendieck realized that one could pass directly to the last step, and that all the geometric properties of a scheme are encoded in the category of étale sheaves. This category belongs to a particular type of categories that he called "toposes."

Here, then, is the last act of the play. Grothendieck had noticed that the sheaves on a given space formed a category that basically had the same properties as the category of sets. But Kurt Gödel and Paul Cohen had already demonstrated that there were various nonequivalent models of set theory. It was thus natural to explore the relations that might exist between toposes and models of set theory. Grothendieck knew nothing of logic and probably despised it just as thoroughly as he did physics. It was for others (especially Jean Bénabou, William Lawvere and Myles Tierney) to solve the riddle: toposes perfectly embodied intuitionistic models of set theory. The principle of the excluded middle is not valid. It is most remarkable that this logic was invented by an illustrious topologist, Luitzen Egbertus Jan Brouwer, and with hindsight, it arises very naturally because intuitionistic logics may be given topological interpretations. ${ }^{33}$

\section{Motives}

There remain the motives. The image to which Grothendieck appealed was a rocky coastline at night illuminated by a rotating lighthouse, one revealing one part of the coast and then another. Similarly, we see the various known cohomological theories, many of which he himself invented, before we return to the source and build a lighthouse that will depict a unified landscape. In some sense, the scientific strategy is the opposite of the one used in the universe of schemes.

\footnotetext{
${ }^{33} \mathrm{~A}$ topological version of the fact that the double negation of a proposition is not necessarily equivalent to it in intuitionistic logic.
} 
Grothendieck never published anything on this subject. He merely made a few remarks. Vladimir Voevodsky made the most ambitious contribution to this area by constructing a category of objects called motives. But in such a category, pieces of objects can migrate like wandering genes. The image of a genetic inheritance seems to me quite relevant. This was made possible by the use of Deligne's definition of weight, the centerpiece in his proof of the Weil conjectures.

The tool created by Voevodsky might have met Grothendieck's expectations, but it was difficult to use. The right tools should be easy to use. Thus what progress has been made has only been accomplished by restricting our ambitions to such objects as mixed Hodge structures or mixed Tate motives. These are expressions of a fundamental group of symmetries, like the GrothendieckTeichmüller group. Even in this small field, there is already an enormous amount of work to be done to unearth inestimable treasures. Grothendieck complained that all this was too economical, too reasonable; he heaped reproaches on the tradesmen from his visionary height. But it seems to me that in the presence of mathematical visionaries, such as Grothendieck or Robert Langlands, the right scientific strategy consists in isolating a piece that is precise and narrow enough that we can make progress, but also sufficiently vast to yield interesting results.

\section{Anatomy of an Author: The Religious Return}

What is striking about Grothendieck, at first, is an expression of suffering: suffering that work was left unfinished, the feeling of having been betrayed by his collaborators and followers. In a moment of true lucidity, he said something like, "I was the only person to have the breath of inspiration, and what I transmitted to those around me wasn't inspiration, but a job. I had workmen around me, but none of them really had inspiration!" The comment is deep and true, but it doesn't explain why he deliberately closed the mouth from which that breath emanated. From what we know of his life today, he is subject to cyclical crises of depression. It seems to me that his capacity for scientific creation was the best antidote to his depression, and that his immersion in a lively scientific milieu (the Bourbaki group and the IHÉS) favored his creativity.

But here I'd like, especially, to mention the religious aspect of his life, which he claims is deep and permanent. He says that he has had visual and auditory hallucinations. He describes these divine apparitions in Récoltes et Semailles, writing that he sings Gospels in two voices simultaneously, his own and God's. It was following a series of these hallucinations or apparitions that he sent out a public eschatological message, unaccountably unanswered. Most disturbing is his obsession with the Devil. He is drafting a report.

\section{Instead of a Conclusion}

Mathematicians see themselves as the most objective of the scientists. If it is to be communicated without distortion, the mathematics must be detached from the mathematician. The mathematician must be allowed decently to disappear. In practice, this disappearance is quite effective.

Grothendieck represents a special case. He lived apart from the world, much more so than the caricatured absent-minded professor. Even in his mathematical milieu, he wasn't quite a member of the family. He pursued a kind of monologue, or rather, a dialogue with mathematics and God, which to him were one and the same. His work is unique in that it didn't efface his fantasies and obsessions, but rather lived in their company and nourished them. He gave us a body of purely mathematical work, and simultaneously offered what he held to be its meaning.

His life was burned by the fire of the spirit, and he continued to search for a country and for a name. I believe the country was Galicia, and the name was that of his father. 